\title{
Ethnography as Ethics and Epistemology: Why American Studies Should Embrace Fieldwork, and Why it Hasn't
}

\author{
Jane Desmond
}

In the US American Studies scholarly community, the last thirty years have produced significant changes: changes in the demographics of our practitioners that are marked by the rise of women and members of US minority groups (racial, sexual, and ethnic) to the highest levels of leadership in the American Studies Association (ASA) and the move of scholarship addressing racial, ethnic, gender, and sexual issues to the center of the field. New specialties have emerged to appear on the programs at conferences, too, including disability, performance, and border studies, and there has been a passionate embrace of popular culture as well. A concern with social class remains present, more often invoked than investigated, but it is still part of our scholarly concerns. More slowly, an acknowledgement of the transnational dimensions of US lives and of scholarship regarding the United States produced outside the United States is emerging.

Methodologically and theoretically, our work has changed too: myth and symbol studies have given way to work influenced by (among others) feminist theories, critical race studies, cultural studies, the new historicism, deconstruction, sexuality studies, poststructuralism, and postnationalist, postcolonial, and transnationalist concerns.

What we haven't done is move substantially closer to the social sciences. For all the invocation of American Studies as an interdisciplinary field/method/discipline/antidiscipline (fill in the blank) in the United States, it remains 
deeply social historical and literary, even if the notion of a literary text has been stretched to include comic books, films, fashion, even sport. It is interdisciplinary, yes, but within a restricted yet unarticulated and largely unexamined scope of allowability - within the humanities. ${ }^{1}$ It hasn't always been this way. The unique legacy of the now-defunct program in American civilization at the University of Pennsylvania long stood for excellence in integrating social science and humanistic approaches. But this model never became the dominant one. It is time for a rigorous reconsideration of this issue.

In this article, I argue that we should actively restructure our research, training practices, and institutional formations to more fully integrate the qualitative social sciences, and especially ethnography, into our work. To do so will not only enlarge our constituencies and readerships, but also enable us to better investigate key issues close to the epistemological and political heart of so much American Studies work: the ways in which social hierarchies and social formations shape and are shaped by the lived experiences of those living in or engaging with the United States as a geopolitical entity or cultural imaginary. I hope to help generate a substantial debate within our field about why ethnography is not a central or even defining practice in American Studies scholarship, although some scholars and some programs are supporting this trend and its institutionalization. What intellectual and field formation legacies might have kept it from becoming central? How might we work intellectually and institutionally to change that, as I think we should?

To persuasively make a case for this transformation within American Studies, I must do several things. First, I want to demonstrate and document the startling degree to which such an absence actually exists in arenas such as publishing and training explicitly denoted as part of the contemporary American Studies scholarly community. I will then consider some of the reasons why this absence might still prevail twenty-five years after John Caughey first called on us in the pages of the American Quarterly $(A Q)$ to move in that direction. ${ }^{2}$ Second, I want to argue explicitly for what can be gained by investing our time, intellectual energy, financial resources, and institutional priorities to make the social sciences, and especially ethnography, more central to our practices. I will suggest that ethnography, as a research practice that demands we engage with communities and actually talk to people about their lives, is both ethically and epistemologically well-aligned with the priorities of American Studies. And finally, I want to consider some of the ways we might approach this transformation, including noting some exciting emergent practices, particularly at New York University (NYU) and University of Southern California (USC), that seem to be pointing in this direction for the future.

In order to sketch broad contours of intellectual practice, I will be extrapolating from my analysis of current American Studies graduate programs in the United States, dissertations in American Studies over a ten-year period, and a decade of publications in the $A Q$. In creating this snapshot of the field, I necessarily risk missing individuals, programs, and publications that serve as counter 
examples. Where possible I will try to acknowledge those, while still maintaining a focus on our most salient contours.

Some counter examples can also be found abroad, and I want to make it clear from the outset that configurations of American Studies (practitioners, publication outlets, training, and modes of institutionalization, as well as political use value) differ substantially across national boundaries, which is how most American Studies associations are organized (i.e., in terms of national contours), and from region to region. In Hungary, for example, literary studies dominate in American Studies circles, and the main journal is called the Hungarian Journal of English and American Studies (HJEAS). On the other hand, in Japan, especially for the founding generations of US specialists who emerged after World War II, political scientists are a strong presence.

My lens is focused on US scholarly communities and institutions linked to American Studies as a specific configuration of knowledge and knowledge producers, whose members are self-nominated as such. However, I will try to make this argument with an eye simultaneously to the multiple configurations of American Studies abroad as well, and will address that briefly at the end of the article.

Finally, I want to acknowledge the difficulty in speaking about American Studies as an intellectual community. Our core claims to interdisciplinarity mean that American Studies intellectual work exists not only within but also outside the range of books, programs, degrees, and journals denominated as such. Especially pertinent for this discussion are the relationships among programs, courses, and publications denoted as "ethnic studies" and those denoted as "American Studies." I will return to this issue below. In order to be able to provide more than anecdotal evidence in sketching the contours of the problem of a lack of ethnography, I will concentrate here on institutionalized components of American Studies as it exists in programs and publications, while acknowledging the necessarily incomplete dimensions of this sketch in capturing the wider flow of scholarship about the United States.

In doing so, I run the risk of critics who abhor any sort of "counting" dismissing this argument as being based on a sort of simplistic positivism. That, however, is far from my goal. Rather, I take up here the challenge of the socalled statistical turn in the humanities. ${ }^{3}$ How do we grapple with issues of measurement and assessment without falling into simplistic positivism? And, to the contrary, how do we move from anecdotal notions to those more fully based on measurement and assessment? To approach this challenge I attempt here to sketch in some details, some measurable parameters, of American Studies as we institutionalize ourselves while simultaneously acknowledging that this "evidence" can only be suggestive, not conclusive. I submit, however, that a dismissal of any such attempts to measure what we do institutionally is equally simplistic and ultimately detrimental to our needed self-reflexive assessments of our field. With these caveats well in place, I offer the following necessarily incomplete snapshot of our multidimensional field. 


\section{Legacies of Disciplinary Origins}

For all the changes in the last thirty years, one thing has remained quite constant in the American Studies scholarly community. Although our demographic profile and our topics and methods have changed substantially in the last three decades, our disciplinary homes (categories by which most jobs are still organized and institutionalized) remain deeply rooted, almost resistant to change.

My analysis of several leading American Studies programs in the United States reveals that a majority of faculty appointed in or affiliated with such programs are still trained in, hold degrees in, or hold faculty lines in literature and history, reproducing the disciplinary origins of American Studies in the United States. ${ }^{4}$ A smaller number of faculty are trained in film studies (with its base often in English departments) and art history, again a historical discipline. Very occasionally, a communication studies or material culture or religious studies specialist will be found on these faculty rosters.

Where are our colleagues who are political scientists? Sociologists? Anthropologists? Ethnomusicologists? Legal scholars? Geographers? Economists? With a few key exceptions (such as the $2005 A Q$ edition, "Legal Borderlands"), ${ }^{5}$ on the whole specialists on the United States from these fields are not attending the US ASA meetings in large numbers; not reading, publishing in, or citing the $A Q$; and not engaging with us in sustained debate, and neither are we reciprocating except in the cases of a few individuals who are committed to such border crossings.

Let me give some data to back up these assertions. Despite the daunting methodological challenges in trying to document an interdisciplinary intellectual landscape like American Studies, I want to offer more than anecdotal evidence to give a more concrete dimension to something that we may already widely sense but have never documented. Aiding me when I began this research in 2006 were Cinda Nofziger and Danielle Rich, then doctoral students at the University of Iowa, who tabulated the disciplinary affiliations of the faculty associated with a dozen of the leading American Studies programs in the country, all of which train PhDs: University of Texas at Austin, Yale University, University of Minnesota, University of Iowa, George Washington University, Brown University, NYU, the University of Michigan, Harvard University, the University of Maryland, USC, and the University of California at San Diego (UCSD). (Of these, UCSD offers a degree in ethnic studies, not American Studies, and USC's program is called American Studies and Ethnicity.) All told, these programs represent both coasts, the Midwest, and public and private research universities, giving a fair representation of a variety of leading programs.

Making comparisons across all of these programs is difficult not only because of their different denominations (American Studies, American civilization, ethnic studies), but also because the interdisciplinary nature of these programs often means that faculty from many disciplines are closely or more 
loosely assembled into programs, not departments - some having core appointments; others joint appointments of American Studies and X, Y, or Z; and still others named as affiliates. In addition, a simple denomination does not tell us much about the actual contours of an individual faculty member's research. Despite these distinctions (which are hard to capture working solely from the statistics provided in the The Guide to American Studies Resources, formerly published by the American Studies Association or on program Web sites), several patterns clearly emerge. I do not claim them as definitive, nor do I wish to suggest any sort of simplistic positivism. However, even given the limitations of the data, the possibilities of some changes in the last few years, and the complex ways that graduate training is actually organized, these patterns emerging from the 2006 analysis are suggestive, and they are striking.

Approximately 41 percent, on average, of all faculty associated with these twelve leading programs have appointments in English or history. Yale and Iowa are even higher, with roughly 66 percent and 62 percent of such appointments, respectively. UCSD is lower, at approximately 33 percent, in approximately the same range as Minnesota, Maryland, and Brown. University of Texas at Austin is the lowest at less than 20 percent, and at least as reported in the Guide, is the outlier on this scale, being the only program with less than one-third of its faculty clustered in English and history.

But even for those programs on the lower end of this scale, there emerged no other cluster of faculty so large. While English and history professors may not be a majority, they still usually retain a plurality. In other words, and not surprisingly, the combined power of professors trained in English and history is the largest recognizable cohort at all of these programs. The rest of the affiliated faculty are spread across a wide range of specialties, usually in ones or twos. I interpret this to mean that such faculty are available to the individual student but are not torquing the program toward their disciplines. ${ }^{6}$

It appears - at least structurally - that history and literature retain a clear dominance and that other associated faculty and their areas of passion and expertise remain tangential to the core of our practices, even now. Note that many of these cognate areas are in the social sciences and engage in a variety of methods of qualitative and quantitative analysis that a majority of our PhDs are not regularly trained in, although some individuals may be. This represents an unrealized potential for restructuring our programs and for new types of knowledge production.

I am sure that each of us can name those in one of those social science disciplinary homes whom we count as fellow scholars of the United States or whom we consider fellow travelers. We may even assign some of their writings in our courses or cite them in our bibliographies (usually very sparsely-Clifford Geertz from anthropology perhaps, but probably not George Marcus). But these exceptions remain just that. As fields of knowledge - with their own histories and commitments to certain questions and not others, certain methods and not others - it is not necessary, we find, to engage deeply with the social 
sciences. ${ }^{7}$ And while the broadest thrust of my argument urges us to consider qualitative and quantitative methods drawn from the social sciences, including those associated with surveys, data mining, interviews, and statistical analysis of aggregate data when appropriate to our research questions, I want to focus in this article on one special aspect of these methods: ethnography and fieldwork - engaging directly with communities whose activities, beliefs, aesthetics, politics, interpretive practices, and everyday lives we are endeavoring to better understand.

\section{Defining Ethnography and Fieldwork}

There is no one simple definition of either fieldwork or ethnography. As John Caughey has pointed out, both anthropology and some strands of sociology, especially the Chicago School of the 1920s-1930s, developed methods of research at the University of Chicago that involved investigations into particular communities, such as Polish immigrants, waitresses, shop clerks, and street gangs, or issues associated with those communities, and did so through direct contact between researcher and members of those communities.

Over the last eighty years or so of anthropology, this research technique developed into a predilection for long-term immersion, usually of a year or more, in a community by an outsider to that community. Depending on the school of thought - structural anthropology, functional anthropology, cognitive anthropology, symbolic anthropology, and so on - the goals are or have been somewhat different, as John Caughey explains in his 1982 article "The Ethnography of Everyday Life: Theories and Methods for American Culture Studies."

Various schools attempt differently to understand the learned systems of meaning that construct notions of reality, or to discover shared public codes of meaning, or to analyze cultural practices as responses to environmental or economic situations. But what remains the same is a recognition that direct contact is essential to understanding the meanings people make in their worlds and the actions, beliefs, and ideational, social, and environmental structures that shape those worlds.

Implicit in this is the deep belief that such understandings, though always incomplete, are important-politically, ethically, and epistemologically. From this point of view, it is not enough to analyze a novel, a painting, a building, a film, a genre, an event, a technology, or a social movement without simultaneously trying to understand not only the social, political, economic, and ideological conditions of its possibility but also the meanings people attach to it, their agency, and the uses they make of it as a way of making their world.

When we analyze events, documents, and cultural products primarily through reference to other events, documents, and cultural products, we situate these as "texts" to be read through a variety of interpretive methods. That is, we read potential effects off of and through the textual structures in a specific historical moment, but this does not necessitate engaging with the people 
who make, use, refashion, and interpret them. By peopling our analyses, we are more able to see cultural products as embedded in networks of cultural and social processes - in action-leading us toward what I would call a more performative understanding of daily life.

Akhil Gupta and James Ferguson put it this way: "Fieldwork's stress on taken-for-granted social routines, informal knowledge, and embodied practices can yield understanding that cannot be obtained either through standardized social science research methods (e.g., surveys) or through decontextualized readings of cultural products (e.g., text-based criticism). . . One does not ... need to grant an unwarranted epistemological privilege to face-to-face interaction in order to appreciate the virtues of a research tradition that requires its practitioners to listen to those they would study, and to take seriously what they have to say."

One of the chief benefits of ethnography is that it enables us, indeed forces us, to engage with the messy complexity of lived experience. In doing so, it can also trouble our theoretical formulations, especially if they threaten to become too streamlined. As anthropologist Kathleen Stewart suggests in her book Ordinary Affects, "the terms neoliberalism, advanced capitalism, and globalization ... and the five or seven or ten characteristics used to summarize and define [them] in shorthand, do not in themselves begin to describe the situation we find ourselves in." Arguing for attention to peoples' actions, feelings, and perceptions in daily life, she defines the ordinary as "a shifting assemblage of practices and practical knowledge, a scene of both liveness and exhaustion, a dream of escape or of the simple life." It is, she tells us, "a moving target . . . a sense of sensations that incite." ${ }^{\prime 10}$ Fieldwork can help us approach that moving target.

Princeton-based anthropologist Joao Biehl further underlines this sense of complexities in flux and emphasizes its importance eloquently when he argues for the necessity of fieldwork in understanding how lives are actually lived. Fieldwork not only helps us describe daily lives, but it also helps us theorize social relations. He writes: “As I see it, ethnography's unique theoretical force lies in recording competing rationalities and vital experimentations, in conceptualizing fine articulations of worlds, differentiated, in flux, and impending. The ethnographer brings into view the immanent fields - leaking out on all sidesthat people invent to live in and by." Further emphasizing the notions of agency that so many of us in American Studies are committed to embracing, he writes: "Such immanent fields of action and significance are mediated by power and knowledge, yet they are also animated by claims to basic rights and desires. And in bringing into public view these localized and multidimensional fields of engagement and possibilities, always on the verge of being sealed off or foreclosed, the ethnographer still allows for some general principles to surface (or, for that matter, to become irrelevant)."

In other words, individuals and communities actively theorize how the world works from their point of view and attempt to intervene in realms of power that structure their daily lives. Being attentive to these ways of mak- 
ing sense of the world, that is, to daily theorizing and action, is in line with the American Studies scholarly commitment to explore the interlocking workings of knowledge, power, institutions, and cultural practices, with an eye toward illuminating and documenting possibilities for improved social justice. Fieldwork, working with and in communities, to understand and document their theorizations of and interventions in the workings of power can exemplify American Studies scholars' long-standing commitments to social change. Biehl puts it this way: "Grasping social fields and subjectivity as becoming - rather than determination - may be the key to anticipating, and thereby making available for assessment and transformation, the futures and forms of life of emerging communities." ${ }^{11}$ In this last point, Biehl, a medical anthropologist working with HIV-positive communities, emphasizes the possibility that the scholar's research may be of direct use to the communities he or she is working with as well.

\section{Pitfalls and Possibilities in Fieldwork}

Among the research techniques associated with fieldwork are participant observation, direct formal interviews, and the development of interpersonal relationships with interlocutors from a community, however defined. These may include a recording of observations, interlocutor's statements, interviews, impressions, hypotheses, and an interpretation of these results. This research is done within a theoretical framework that accounts for and demands a selfreflexive awareness of the researcher's own position and the bases of authority from which he or she presumes to speak and to ask questions.

As used in anthropology, the term "ethnography" carries with it an implicit historical reference not only to "being in the field" as opposed to being in the controlled conditions of a laboratory, but also to attempting to create a "thick" holistic account and communicating that account through monographs (ethnographies). Margaret Mead's Coming of Age in Samoa is an early classic example widely known outside anthropological circles. ${ }^{12}$ But, for at least twenty-five years, the practice of ethnography as a potentially imperialistic mode of representing those who cannot, or are not allowed to, represent themselves in wider public discourse has been roundly critiqued, as have those aspects of its past that contributed to colonialism. Some of the sharpest critiques have come from anthropologists themselves. Feminist and postcolonial critiques have been a central part of these vigorous debates within anthropology. ${ }^{13}$

It is now widely recognized among anthropologists that the complexities of power and the simplistic assumptions of insider/outsider status must be carefully and explicitly addressed, as many authors have asserted. ${ }^{14}$ And the days of the presumptive all-encompassing monograph are long gone, replaced by self-reflexive accounts of research. These accounts are much more restricted in their goals and claims and more collaboratively produced by scholars and community members, with increased attention to the ways in which the academic 
work can ultimately contribute not only to scholarly knowledge but also to the needs of the community with which it is engaged. ${ }^{15}$

In addition, anthropologists have recently been deeply and at times aggressively engaged in intradisciplinary debates about the fetishizing of "fieldwork" and "the field" as the historical sine qua non of the discipline of anthropology. Important texts like George Marcus's Ethnography Through Thick and Thin and the edited collection by Akhil Gupta and James Ferguson, Anthropological Locations: Boundaries and Grounds of a Field Science, are key contributors to these debates. ${ }^{16}$ It is beyond the scope of this article to attempt to summarize those debates, but I do want to note that some of the recurring themes include not only the lingering potential for an exotification of difference that would define "the field" as the home of bounded communities of individuals seen as fundamentally different from the anthropologist, but also the shifting contours of and theorizations for locality/globality that yield fields as unstable locations, unmoored from geographical sites.

Communities now can be conceived of as groups of like-minded individuals meeting online, as transnational nodes of diasporic communities in motion, or even as structures for the production of scientific knowledge about genomes that are linked to but not limited by research institutions, organizations, funding agencies, and publishing outlets. As nonstatic groups affiliated on the basis of shared belief, place, practices, relationships, or interests, communities are everchanging entities.

These shifts in social structure and in the structures of production (of identities, capital, commodities, political power, and knowledge), or at the very least in our awareness of them and their constitution as our objects of investigation, require new conceptions of fieldwork. George Marcus and others ${ }^{17}$ have argued for the conduct of "multi-cited ethnographies." As Marcus writes: "Multi-sited research is designed around chains, paths, threads, conjunctions, or juxtapositions of locations in which the ethnographer established some form of literal, physical presence, with an explicit, posited logic of association or connection among sites that in fact defines the argument of the ethnography." 18 Not surprisingly, some anthropologists see such a call as a dangerous invitation to lose the depth of personal engagement so long valued by anthropology's conventional insistence on long-term immersion in specific field sites, a point I take up in the following section.

\section{An Ethics and an Epistemology}

While full of these potential pitfalls, ethnography at its best can also be a method with an ethics that demands respectful personal engagement by the scholar with people outside the academy. ${ }^{19}$ Within this larger political framework, I find that "ethnography" emerges for me as both an ethics and epistemology; that is, as an ethics that states that we should actually talk to people, not just analyze their "products," and as an idea about knowledge production 
that asserts that textual analysis alone, no matter how elegant and sophisticated, cannot sufficiently illuminate social practices and social formations in action.

In this article I will use the term "ethnography" to mean research practices that demand serious engagement by the researcher with members of a community or inhabitants of a place (virtual or material) or participants in an institution with which his or her research is associated. In a fieldwork situation, this engagement will most likely be face-to-face and include participant observation. In other research, it may involve more long-distance engagement, supplemented by phone or e-mail interviews or through survey techniques. And while fieldwork in the anthropological sense once meant an extended immersion in a community - at least a year or more - this too is changing as the benefits of shorter-term, multisited, comparative ethnographies have come to the fore. For the purposes of my argument here, I want to be even more expansive in my use of this term, with "fieldwork" referring broadly to direct engagement with the communities one is trying to understand.

On the other hand, I am not advocating a sort of shoddy, quick-hits approach, with the scholar zooming through or dropping into a community just long enough to grab a few quotes and gain a superficial understanding of ideas, beliefs, and practices held dear or debated by that particular collective. It is essential that with fieldwork, as with any other research method, we as researchers be explicit about the scope of the claims we make based on the extent and depth of the evidence that we gain through our research. Sometimes fieldwork will form a central part of our research, demanding long-term affiliation and participant observation with a community or communities. At other times, it may require shorter periods of direct contact and be one research component among many, used mainly as a way of opening new avenues for further research than would have occurred to us on our own. Whatever its role and duration, our analyses must accurately calibrate and explicitly state what we feel can and cannot be reasonably hypothesized and why, based on what we have seen, done, or come to know through our engagement with members of communities.

Other social science techniques, more associated with political science and sociology, may involve the gathering of information not only through surveys but also through data mining with computers and the subjecting of such to statistical manipulations to test hypotheses. These analytic practices can combine quantitative and qualitative methods. Joined with archival research, discourse analysis, visual analysis, and oral histories, these methods can provide ways of further engaging the habitus in which and through which people construct meaning in their worlds.

I regard each of these research methods as potentially useful and, of course, also as having its own attendant limitations and dangers. Ultimately, I am arguing here for an American Studies practice that includes, as one of its core methodologies, being in the field, wherever that field happens to be - down the block or across the country. Engagement with individuals and groups - and actually talking to people-is crucial and is still sorely lacking in our dominant prac- 
tices. ${ }^{20}$ Such interactions can yield more substantive insights than text-based research alone whenever we consider contemporary phenomena because these interactions bring us face-to-face with the necessarily messy, inconsistent, and inchoate realities of daily life in process.

\section{Mapping the Absence}

To drive this latter point home, I wanted to find a way to map the current presence or absence of fieldwork or research methods associated with the social sciences. Because the scholarly community I am analyzing and addressing here comprises those scholars who actively associate themselves with the practice of American Studies in the United States, I am taking as one of my chief measures the contents of the most highly regarded journal in that field in the United States: the American Quarterly. The $A Q$ by no means fully represents all types of work being done in American Studies, nor does it claim to do so, but as the flagship journal for the US ASA, it exerts enormous influence on the field and is received by all members of the organization. It is also read relatively widely abroad. For these reasons, it exerts a strong shaping presence in the field, helping to define not only what is normative but also what is desirable. Because the location of the journal moves from one university to another as editors and the editorial board change over time, there is some fluctuation in emphasis in the type of articles featured, and what was true in the past does not necessarily predict what will happen in the future.

I began working on this research in 2006 and decided to focus on a tenyear span of time. Taking as a data set the number of articles, book reviews, exhibition reviews, and dissertation abstracts published in the $A Q$ over a decade (1996-2005), the following patterns emerged. ${ }^{21}$ While I expected the overall trends, the extent to which ethnography is lacking is striking indeed. Again, I offer these findings neither as numerical positivism nor as a critique of the $A Q$, but rather as one way of measuring a presence/absence that can lead us to further investigation. Given the limitation of quantitative methods in measuring qualitative work, caveats are in order; however, even given those caveats, the following findings are striking and suggest the need for serious evaluation.

1) Of slightly more than 1,000 items (articles, book review essays, dissertation abstracts) appearing during this time period, less than eighty indicate any type of affiliation with ethnographic methods. This is less than 8 percent.

2) The absence is most pronounced in the most prestigious part of the publication - the full-blown single-author articles themselves, of which there are usually four to eight per issue, with the exception of special theme issues. Of 184 articles in the decade under consideration, only three explicitly include mention of ethnographic methods: less than 2 percent.

3) Of the exhibition and film reviews, only one out of thirty-four included any reference to ethnographic methods. 
4) Of 233 book reviews, nineteen included mention of ethnographic methods employed by the authors. Still under 10 percent, this higher number may reflect in part the commitments of then-book review editor Barry Shank, himself a practitioner of fieldwork. ${ }^{22}$

There could be many reasons for these small numbers. Perhaps few scholars are doing this work and thus few submissions using ethnography in some form are received. Or, perhaps those received are rejected because they do not fit the profile of American Studies scholarship. Or, perhaps scholarly work employing these techniques is being published elsewhere, in sociology, anthropology, or ethnic studies journals and not in the $A Q$. Or, perhaps those pieces submitted are not well done because American Studies practitioners may be poorly trained in ethnographic methods. There are many plausible reasons for this absence.

It is important to note that the vast majority of submissions to top-tier journals are rejected, so any meaningful consideration of patterns would occur only if a higher percentage of ethnographically informed work were rejected, and there is no indication that that is the case. Indeed, as past editor of the $A Q$ Marita Sturken noted in e-mail correspondence with me, in fact the editorial board has been well-disposed toward ethnographically based work, but not much has been submitted. ${ }^{23}$

In the last few years, we can begin to see an encouraging trend as several published articles made participant observation or extensive interviews central to their research. ${ }^{24}$ This may be especially clear in several special issues of the $A Q$ since 2006 since it and its board have been based at USC, home to an especially influential ethnic studies cohort whose work and teaching often include ethnographic methods. One such example is the special issue on Hurricane Katrina, "In the Wake of Katrina: New Paradigms and Social Visions," edited by Clyde Woods (now available in book format), potentially signifying a growing trend..$^{25}$

The data are a little different if we pull back and take a snapshot of dissertations in American Studies. Especially intriguing, because more representative of a wide range of $\mathrm{PhD}$ programs, are the listings of 628 dissertation abstracts that appear in the $A Q$ in the ten years under consideration. As far as I can tell, of these, fifty-five utilize (or deem important enough to include in their abstract) some sort of methods associated with ethnography, such as participant observation, interviews, or collecting oral histories. Given the limitations of conducting analyses in this way with abstracts alone, I do not want to make large claims about this. Clearly, these numbers must be regarded as approximate, but the data may be suggestive of future trends: While this number is still less than 10 percent, it is significantly higher than the proportion of roughly 2 percent in the article count. ${ }^{26}$

Yet, without encountering the full dissertations directly, even the abstracts give us a sense of what we are missing by not making ethnography more central to our training and publications nationally. Key questions about social differ- 
entiation, social inequality, labor, material culture, and recent history all can be, and are being, addressed through work that uses immersive fieldwork, oral histories, surveys, extensive interviews, and participant observation. Consider the following listing of ten dissertations - a sample of topics and approaches taken from the total of fifty-five dissertation abstracts appearing in my survey of the $A Q$ contents referenced above:

1) David Cavicchi, "Tramps Like Us: Music and Meaning among Springsteen Fans," American Civilization Program, Brown University, 1996. The dissertation is based on two years of ethnographic research among fans.

2) Jinzhao Li, "Constructing Chinese America in Hawai'i: The Narcissus Festival, Ethnic Identity, and Community Transformation, 1949-2005," American Studies Program, University of Hawai'i at Manoa, 2005. The author includes material based on archival research, interviews, and extensive participant observation.

3) Eric Porter, “'Out of the Blue': Black Creative Musicians and the Challenge of Jazz, 1940-1995," program in American Culture, University of Michigan, 1997.

4) Amy Bowles-Reyer, "Our Secret Garden: American Popular Young Adult Literature in the 1970s and the Transmission of Sexual and Gender Ideology to Adolescent Girls," Department of American Studies, George Washington University, 1998. The author developed written questionnaires for female graduates of the Sidwell Friends School in Washington, DC.

5) Anne Birgid Globensky, "At Home in Baltimore: An Ethnographic Approach to the Study of Lumbee Domestic Material Culture," American Studies Department, University of Maryland, 1999. The author engages with seven Lumbee households via stories told about their living rooms.

6) Bonita Hampton, "A Comparative Study of Risk Factors Associated with Exposure to HIV among a Sample of African American Women," Department of American Studies, SUNY Buffalo, 1998. The author uses personal interviews to combat stereotypes sometimes associated with African American women's contact with AIDS.

7) Matthew Pustz, "Fanboys and True Believers: Comic Book Reading Communities and the Creation of Culture," American Studies Department, University of Iowa, 1998. The author conducted extensive interviews with fans.

8) John Howard, "Men Like That: Male Homosexualities in Mississippi, 1945-1985," Graduate Institute of Liberal Arts (Program in American Studies), Emory University, 1997. The author used oral interviews.

9) Karla Erickson, "Paid to Care: Selling Service, Smiles and Community in American Restaurants," American Studies and Feminist Studies Programs, University of Minnesota, 2004. The dissertation is based on three years of participant observation and interviews with workers, managers, and customers in local family restaurants.

10) Deborah Whaley, "The Cultural and Counterpublic Sphere Work of Alpha Kappa Alpha Sorority," American Studies Department, University of 
Kansas, 2002. The dissertation includes a chapter based on ethnographic analysis of step dancing and hazing.

Other topics emerge among these fifty-five dissertations, less anchored in specific race, class, gender, or sexuality issues and communities: commuters on the DC beltway, parents in transracial adoptions, the Fourth of July and working class nationalism on the Iron Range in Minnesota, emerging forms of academic writing assessed through interviews with graduate students, women's relations through a study of quilt-making groups, tailgating as ritual at Ole Miss, life experiences of homeless men in Albuquerque, tourism and social conflict in a small Southern town.

These types of studies both engage and expand on some of the primary areas of American Studies research: race, gender, sexual identity, social class, indigeneity, and nationalism. They also open new avenues as well, bringing us studies of microregions like the DC beltway, a small town looking to tourism as a way of surviving, and even ethnographies of the academic world itself.

Cultural products like comic books, girl's literature, quilts, and music are examined in these dissertations, not only as objects of study but also as objects made, circulated, remembered, consumed, and rejected. Lived experience, whether of decorating a living room in Baltimore or adopting across racial lines, form the guts of many of these studies. And, working with oral history and memories, the contemporary context can stretch well back into the earlier part of the twentieth century, bringing history to bear on our understanding of the present.

One reason so few dissertations using ethnographic techniques have appeared in this count is the lack of training in ethnographic methods offered as a constituent part of a majority of US American Studies PhD curriculums and the lack of affiliated faculty who actively structure their research that way. There are important exceptions (among them courses at California State University at Fullerton, University of Texas at Austin, USC, and NYU), but despite the exciting work of scholars from these institutions and others and the legacy of the faculty and students at University of Pennsylvania (Penn), ethnographically based work remains unusual in American Studies programs in the United States, and has, as I have demonstrated here, yet to attain a critical mass of either practitioners or publications. It has not as yet reshaped the central questions or research techniques associated with American Studies in a profound way.

\section{Ethnography "in" American Studies}

Every research design presupposes certain questions to be answered, and to the contrary, every approach to research makes it possible to answer some questions and not others. Ethnographic methods allow us to pose and answer types of questions that archival research, textual analysis, film analysis, and any sort of theoretical approach to analysis based on cultural products alone do 
not. Ethnographic methods help us to understand social processes in motion, as living responses to changing histories and situations. ${ }^{27}$

I am certainly not the first writing from within the American Studies community to urge us to take ethnography seriously. John Caughey made the case eloquently in the $A Q$ in 1982. He articulates several persuasive reasons why we should engage in ethnographic studies:

1) Ethnography can greatly contribute to a better descriptive understanding of the pluralistic nature of the complex society in which we live; in other words, ethnography helps, even makes, us deal with a social complexity that textual analysis alone might miss.

2) Ethnography is crucial for developing the sophistication of our cultural theory. "Through sustained firsthand contact with ongoing institutions, communities, and social scenes" Caughey asserts, "we can develop, text, modify, and refine our theoretical constructs." In a sense, we are testing our theoretical paradigms "in the field" for their explanatory power. ${ }^{28}$

3) "When doing fieldwork, the ethnographer often confronts face-to-face people who live other realities." Thus, it can be an affective and transforming experience for the researcher and for those who read her research. Fieldwork demands that we constantly test our own assumptions. And finally, Caughey states, "ethnography enhances our understanding of the power and complexity of cultural forces," as we see these forces of social hierarchy, economic disparity, and political disenfranchisement or hypervaluation in action. ${ }^{29}$

At the time, Caughey was teaching at Penn, in its American Civilization program, after having received a $\mathrm{PhD}$ there in anthropology. Penn's program, from its earliest years, had been unique in its insistence that the social sciences be part of the emerging formulation of what we now call American Studies. In an article in the $A Q$ in 1970 delineating the history of the department from its origins as an undergraduate program in 1937, Murray Murphy described the required graduate proseminar as including four sections: an introduction to the theory of culture, the use of literary materials as evidence, the study of material culture, and "the application of social science theories to historical data." In addition, students were required to take courses in American ethnography, selecting from the ethnography of certain regional and historical specialties, such as that of colonial Massachusetts in the seventeenth century. ${ }^{30}$ But as important as this formulation was, it did not become a dominant national model as programs solidified their stances across the country to focus on literature and history.

The case had to be made again eight years later when Caughey's piece was followed by a related push by George Lipsitz, who in his influential 1990 article, "Learning to Listen," discussing the potential imbrication between European strands of cultural theory and US-based American Studies, urges us to attend closely to the voices of arts practitioners, especially those in popular culture. ${ }^{31}$ Arguing that a theoretically informed American Studies should begin by listening for the sounds that Toni Morrison describes as capable of breaking the back of words, Lipsitz insists these illuminating moments are to be found 
"within the concrete contests of everyday life ... accessible by listening to what is already being said (and sung and shouted) by ordinary Americans." As he argues, "American Studies would be served best by a theory that ... grounds itself in the study of concrete cultural practices, that extends the definition of culture to the broadest possible contexts of cultural production and reception $\ldots$ and that understands that struggles over meaning are inevitably struggles over resources."

Despite their power, echoing that of later statements of anthropologists Joao Biehl and Kathleen Stewart cited above, Caughey's and Lipsitz's calls to do community-based research on lived experience have not substantially transformed the practice of American Studies in the United States nor the training programs these scholars depend on. Nonetheless, there are key exceptions, and here I want to offer a necessarily incomplete listing of some scholars active in American Studies departments, programs, and institutions nationally whose work is based in large part on the use of ethnographic research: Kate Dudley at Yale University; Rich Horwitz, for many years my colleague at the University of Iowa; Jay Mechling at University of California-Davis; Janice Radway at Northwestern University; George Lipsitz at the University of California at Santa Cruz; Arlene Davila and Andrew Ross at New York University; Tricia Rose at Brown University; Barry Shank at Ohio State University; Joe Austin at Bowling Green State University; Jose Limon at the University of Texas-Austin; Cary Lane at University of California-Fullerton; and Ben Chappell at University of Kansas. But these individuals, despite the important influence they have had as individual scholars, have not yet created a critical mass strong enough to dramatically, nationally, transform the institutionalized training practices of American Studies.

Neither the legacy of the social science base of much of the highly regarded American Civilization Program at the University of Pennsylvania nor the influence of key oft-cited but rarely duplicated approaches in well-known canonical American Studies texts, like Janice Radway's Reading the Romance, ${ }^{32}$ transformed the practices of American Studies. The obvious question is "why?" And will my call for us to move this debate to the forefront of our discussions have any different effect in today's climate?

These questions were raised by very thoughtful readers of this article in draft form, and I do not have the answers here. It will, I believe, take a sustained, collective, national discussion to tease out some compelling answers to these questions because they lie in the intellectual and institutional histories of American Studies, anthropology, and sociology as they have developed in this country. This work will be crucial if we are really to make a change this time around.

I have been arguing that the work of American Studies is well aligned with the types of knowledge production and political engagements that so many of us in this intellectual community seek and that ethnographic methods can provide. It may be that the scholarly configurations of those engagements-what 
one reader termed the "field imaginary" of American Studies-has mitigated against this in the past. Delineating the historical trajectory of that field imaginary (or field imaginaries) clearly lies beyond the scope of this article, but it may well be central to the debates that I hope will arise from it. As one reader suggested, to the extent that the remit of American Studies has been about a nation and the focus of much ethnographic work has been small-scale community based, there may have been a perception of an uneasy fit. The practice of anthropology, however, has continued to evolve from its early focus on the production of written ethnographies about small-scale societies to encompass studies of global circuits of power, products, ideas, and people. Or, perhaps, as another reader suggested, the impact of British cultural studies with its very particular etiology may implicitly limit the ways that we conceive of our research questions, making them less amenable to sustained fieldwork. All of these possibilities and others need to be examined. And ultimately, we must be convinced that the new types of research questions we might ask would be compelling to us and worth the discomfort of change.

\section{What We Are Missing}

By now I hope that I have persuaded readers that the social sciences in general and ethnography in particular are dramatically absent from institutionalized American Studies. I have sketched some of the terrain in debates about ethnography and argued for its (self-reflexive) inclusion as a core component in our research and training programs. I have offered some brief indications of the expansion of understanding that can come out of such work, as indicated in the dissertations and scholars referenced above. Ultimately, however, we won't change things unless we see the value in doing so as being worth the cost of the effort involved in transforming our projects and programs. So let me close this section with one more complete case study of just what we are missing. The bottom line is that ethnography can bust us out of our own assumptions-ideological, political, and analytical. It can force us to see and think differently and ultimately to come to different conclusions.

Texts may "talk," but they don't "talk back." They don't necessarily challenge us and our thinking as direct interlocutors. Joining a community to do fieldwork, when we are allowed by that community to do so, immerses us in the everyday contradictions and fault lines of being that structure social interactions. And participant observation means not just talking, but doing, as well. As Massachusetts Institute of Technology (MIT) anthropologist Heather Paxson puts it: "Not only do we ... talk to people, we do things with them, alongside them, and ask them what they think. So it's about connecting aspects of social life that people don't always connect. ${ }^{{ }^{\prime 33}}$ In the flow of doing, and of analyzing multiple events over time, we can come to see that what we might have expected from our analysis of visual, aural, or textual documents doesn't tell the whole story. 
Tanya Erzen's book, Straight to Jesus: Sexual and Christian Conversions in the Ex-Gay Movement demonstrates just this sort of surprising conclusion. ${ }^{34}$ Working on her dissertation in American Studies at NYU, Erzen spent eighteen months with the New Hope Ministry in California, the oldest of five residential programs in the United States devoted to transforming gay Christians into ex-gay Christians. She combined formal interviews with nearly fifty people with months of attending events such as meetings, group dinners, and organized sports outings and by joining the daily life of the organization by assisting with the Web site in the organization's office. Ultimately, she shared her findings in dissertation form with many of the members of the organization and responded to their comments.

The most striking finding in this book is the fact that many participants regarded New Hope as a pocket of resistance to the antihomosexual beliefs of the conservative evangelical churches. Although the stated goal of the organization is to help people overcome their homosexuality and return to heterosexuality, it recognizes homosexuality in a way that more conservative churches do not. It assumes that homosexuality is not a disease to be "cured" through religion but rather a condition that many in the program will forever struggle with. The way from gay to ex-gay is (they say) not simply by rejecting gay desires as evil, but through deepening ones' faith in God. In fact, the meetings were full of stories about gay life, confessional narratives of gay sexual experiences, and richly textured descriptions of gay relationships that many of the men-some who had been isolated in rural areas without access to a gay community — had never otherwise experienced.

For some men, New Hope was, ironically, the most gay-acknowledging community they had ever been a part of. Many stayed for years precisely because of that. Some came to actively reject the calls of the conservative Right for antigay legislation. In fact, as Erzen asserts, "many found themselves more sympathetic to gay rights than to the Christian right." An analysis based on texts produced by New Hope would never have revealed these surprising insights. ${ }^{35}$

This complexity, like the messiness and the unexpected affect that Stewart finds in the ordinary, bring us closer to understanding how politics really works in peoples' lives as they negotiate acts of belonging. Ultimately, Erzen finds that both the Christian Right and some liberal political stances of rights-based discourse are equally limiting in the conceptions they carry about how human sexuality is experienced. She concludes: "The lives of ex-gay men and women demonstrate that sexual and religious identities are never static or permanent. This idea must become a part of the larger public discussion about sexual rights in order to imagine a world in which everyone is entitled to the full benefits of citizenship." ${ }^{36}$

As a scholarly community deeply committed to political change that will yield greater social justice, American Studies can further its own ability to contribute to these changes by drawing more of its analyses from daily life, as Erzen has. This type of work, as Caughey notes, will also constantly interro- 
gate our theories if we listen carefully enough; this may be one of its greatest potential contributions. As David Schneider puts it: "It's not exactly that we go out [into the world] to test hypotheses, but the field situation does offer a [productive] resistance to our preconceptions, and our theorizing comes out of our engagement with that situation." ${ }^{37}$

\section{When Inertia Is Resistance}

If the benefits of this type of work reinforce the political goals of the American Studies project, why have we seen so little change in the twenty-five years since Caughey made his call for action? Earlier, I referenced the issue of the field imaginary and the historical trajectory of its intellectual histories. But there are related institutional issues.

Some of the reasons for this inertia emerged in roundtable discussions titled "Ethnography In/And American Studies" that Janice Radway and I organized for the 1997 US ASA meetings. We invited several participants, half of them trained as anthropologists and working in the United States on cultural issues aligned with American Studies priorities and half trained in or teaching in American Studies programs or affiliated units (Moshe Shokeid, Katherine Dudley, Virginia Dominguez, Brenda Bright, and Joe Austin).

While much of the audience discussion concentrated on what ethnographic and fieldwork approaches might bring to an enlarged version of American Studies, including studies of creative community building through performative actions like graffiti tagging, cruising in low-riders, and building a gay synagogue in New York, institutional and attitudinal limitations soon emerged. At one point, someone commented that "we could never do that in an English department [despite our interest in graffiti or customized cars as texts] because it would take too long for our students to graduate if they did fieldwork [i.e., studying those texts in action]. We couldn't support them monetarily."

While I can't reproduce the exact words of that moment here, the gist of this comment has stuck indelibly in my mind. I think it is fair to say that similar attitudes might emerge in history departments, even among those working in the contemporary period, and in many American Studies programs as well. As long as our point of reference for what normative graduate research looks like remains going to the library or intensively but relatively briefly consulting a number of archives, the acquisition of the special skills needed to conduct ethnographic work responsibly, and the time, travel, and money it often takes to do it, seem unimaginable, or at least unsupportable. Institutional change is needed, not just the existence of exemplary scholarship by a few individual faculty across the nation. 


\section{Distaste and Discomfort?}

There is another possible reason for resistance to fieldwork, and this too emerged for me in the form of an offhand remark several years ago by a distinguished colleague in literary studies who had begun working on body piercings. After a talk, someone in the audience asked if the speaker had talked to those getting the piercings. The response was a visceral "ugh, NO! I wouldn't want to hang out with those people!" I relate this not to criticize the scholar, but to point toward what is an undiscussed yet potentially important issue: the role of cultural capital and cultural comfort in shaping our intellectual work. I have only anecdotal evidence to offer here at this point, but I think this issue deserves further discussion and reflection.

A majority of academics are middle class or upper middle class, if not by family of origin then by educational attainment. ${ }^{38}$ Yet many of the issues we struggle with through our scholarship in American Studies today involve most directly groups whose membership in the middle class is complicated or limited by one or several modes of disenfranchisement (including racial and ethnic backgrounds, social and economic class, immigrant status, and so on). Does this potentially cause cross-class discomfort that makes it easier to analyze the lyrics of a rap song than to speak with rappers? Is there a similar discomfort for the majority of US college faculty who are to the middle or left of center on the political spectrum? Is it easier to analyze the rhetorical construction of so-called pro-life activists without attending their meetings? Of the National Rifle Association? Of white supremacist groups? Each of us brings a distinctive personal genealogy to our work. Have we adequately assessed the ways in which our personal comforts and discomforts shape our engagement with or avoidance of community interaction as a part of our research processes? This is a challenging topic to discuss and would be an important conversation to have as we assess why a move to adopt ethnographic methods has been so slow..$^{39}$

Let me be clear here. I value rhetorical, discursive, and archival analyses. I value the analysis of visual texts. One of our strengths lies precisely in the elegance, precision, and subtlety with which so many of us can "read" these types of texts, and this is a highly trained skill that our colleagues in anthropology and sociology and political science often lack. Indeed, it is something that our colleagues in those disciplines should be looking to us for. I am not for a minute suggesting that we should give up these strengths. Rather, I am saying that it is time for us to add to our strengths by learning to go into the field, that is, into the world, to embed our research on social issues - so often the ultimate bottom line of our textual analyses - in the social lives of living communities.

I want to suggest here that we open out our point of reference from the English department to the anthropology department in terms of these last factors. If time in the field, whether that be 1,000 miles away or in our own communities, were regarded as normal, then we would restructure notions of appropriate progress toward degree, travel funding, the acquisition of needed languages, 
and so on, to enable and perhaps even nurture those possibilities. I am arguing that we should do so, so that we and our students have the material conditions possible to ensure good, in-depth work. We should redesign our programs and institutional structures as needed to facilitate this so that ethnography takes its place firmly in American Studies work as one possible mode of research among others, one that I believe is intensely complementary to the historical-, literary-, and cultural studies-based research that dominates in most programs today and to the political commitments that underlie our dedication to the production of knowledge.

\section{Redesigning American Studies Programs}

Such a change means redesigning American Studies programs to include a core exposure to social science research methods in general and to ethnographic research in particular. It means cooperating with anthropology departments in providing expertise in fieldwork methods. It means enlarging the types of texts we assign, review, cite, and engage with. It means inviting anthropologists and sociologists to join us in dialogue at the ASA meetings and creating viable and visible forums for them to do so. It means stretching our own capacities through new training, enabling interested faculty to conceive of and carry out new research projects that include an element of fieldwork when it is appropriate to what we want to find out. It means ensuring that our faculty and students are deeply steeped in and cognizant of the ethical complexities of engaging with living communities as part of their research, attentive to their obligations to these communities, and cognizant of the ongoing debates about how to conduct fieldwork. ${ }^{40}$ All of these impulses require and are responsive to institutional reshaping on a national scale.

There are signs that the contours of American Studies may change in this way in the future, and they are most marked in the structure of the PhD programs at NYU and USC's Department of American Studies and Ethnicity. It may be that the relative newness of these programs, combined with their emphasis on urban sites as both their locations and their sites of intellectual engagement, particularly facilitate the integration of the social sciences. The NYU department includes two anthropologists on its core faculty, Caitlin Zaloom and Arlene Davila (who is jointly appointed in American Studies and in anthropology). Several other members of the anthropology department, including Rayna Rapp, Emily Martin, and Faye Ginsberg, hold affiliate appointments and bring strength in science studies and media and community studies. Founding director of the NYU program, Andrew Ross has produced recent works based on extensive fieldwork in Florida and in China. ${ }^{41}$

In addition, the core graduate curriculum includes seminars titled The Practice of Ethnography and Linguistic Anthropology through a cross-listing mechanism with anthropology. And finally, the program asserts that three component methodologies are central to its students: ethnography, historical analy- 
sis, and critical theory. It facilitates group research projects, often community based and focused on urban issues, that engage faculty and students and result in published collections.

An even newer program at USC, which recently graduated its first cohort of $\mathrm{PhDs}$, goes even further. Its core faculty, all of whom hold joint appointments in their home department and in American Studies and ethnicity, includes about ten professors (one-third) in the social sciences (anthropology, psychology, sociology, political science, geography). The program requires its students to develop competency in two methods out of six possibilities: literary/textual analysis, historical/archival analysis, ethnography, visual analysis, spatial practices and analysis, and quantitative analysis. Not only is ethnography explicitly named as a methodology of choice, but several of the other options lean toward the social sciences as well.

An important part of the strategy at USC appears to be not only what they offer and require but also whom they admit. Recent graduate cohorts bring an exceptional diversity of intellectual and professional backgrounds, including those with degrees in sociology, law, geography, anthropology, and public policy in addition to more expected backgrounds in literature, American Studies, and ethnic studies. By selecting for this previous exposure to social sciences, the program automatically brings these disciplines and perspectives directly into the classroom discussion, even when the focus is on the humanities.

Not surprisingly, a number of research projects and dissertations underway or recently completed at USC use ethnographic methods. These include Hilary Jenks's dissertation "Home Is Little Tokyo: Race, Community, and Memory in Twentieth-Century Los Angeles," Imani Johnson's multisited ethnographic project on improvisation in hip hop-derived street dance "Take Me Higher: Blackness, Kinesthetic Knowledge, and Global Connection in Hip Hop Dance Circles," and Lata Murti's dissertation on ethnoracial identity formation of firstand second-generation Indian immigrant doctors in Southern California, based on fifty-two interviews. It remains to be seen whether the new work coming out of these institutions will create enough of a critical mass to drive substantial institutional change or whether the situations at NYU and USC will be like that at Penn-important programs, but not necessarily changing the national parameters of our field to make social science engagement normative.

Ethnic studies programs, which, like women's studies and sexuality studies programs, often include a commitment to community engagement, may be some of the most fertile ground for immediately expanding the role of ethnography in American Studies intellectual work. Indeed, discussions of the issues raised by this article by the editorial board of the American Quarterly suggested that some scholars believe that a lot of ethnography in American Studies is already happening, but it is happening in ethnic studies, ${ }^{42}$ and that this work is underrepresented in my discussions here. If that is so, then the role of the $A Q$ in representing the full range of work in American Studies as the flagship journal of the ASA falls into question as well, for as we have seen, at least as based 
on my analysis of a ten-year period, the general paucity of ethnographically based work in the $A Q$ is striking. However, a new trajectory may have been developing in the last several years, as more articles embracing ethnographic methods are appearing. The long-term trajectory of this development cannot yet be projected.

The institutional and intellectual dividing lines between ethnic studies programs and American Studies programs in the United States are in flux: at times, the programs operate in collaboration, at times in competition for limited resources - all existing as generally smaller programs on campuses. And the layout of such programs and their relations vary from campus to campus, a topic much discussed at American Studies meetings in the past decade and a half and specifically addressed by a task force. The intellectual and institutional politics and histories of these complex relations exceed the range of this article. However, to the extent that ethnic studies and American Studies programs collaborate, or are merged as at USC, the current home of the $A Q$, ethnic studies programs may be in a position to lead the transformation I am calling for here. Ethnic studies (and women's studies) programs often include sociologists and cultural geographers as well as historians and literary scholars on their jointly appointed faculty. They often include community engagement efforts as part of their ongoing activities. As such, their affiliations with the social sciences overall may be more comfortable than for many American Studies programs in the United States. Collaborations may offer an accessible way of extending ethnographic training and research.

However, before jumping to the conclusion that because this work exists in ethnic studies, as it is currently instantiated on campuses, it is present in American Studies programs all across the country as they currently exist, we must consider the degree to which the scholars and scholarship associated with these programs on a case-by-case basis are actually mutually read, cited, and joined together in graduate training and teaching on any particular campus. Do scholars perhaps continue to read, cite, and assign texts that are similar to their own disciplinary training? Do literary scholars assign texts by sociologists? If so, are they comfortable evaluating these texts? Here the tensions between what scholars say and do and what is actually supported institutionally on their campus and beyond need to be carefully interrogated in order to build collaborations and to not assume that they already exist just because it makes sense that they should. Yet, collaborations around the further development of ethnographic work on the United States among ethnic studies, American Studies, and women's/gender studies programs potentially offer promising arenas for the future.

An additional impetus, and the potential for funding for American Studies and ethnic studies programs, also lies in the current national push for community engagement by universities. As the current financial meltdown shrinks university budgets, the call for community accountability and engagement may increase, providing fertile ground for collaborative research with and within 
communities, a practice that scholars located in American Studies, ethnic studies, cultural geography, urban planning, sociology, and anthropology may well share, thereby forging new intellectual work while successfully sustaining themselves financially during an especially challenging period. In this sense, our reconsideration of ethnography and the social sciences now may be especially timely.

To support these new research and training initiatives, for ourselves and our students, we must actively address the potentially limiting logistical concerns as well. We must find funding for field-based projects by guiding our students toward the Social Science Research Council, and even the National Science Foundation, and not just the National Endowment for the Humanities for fellowships. To successfully do so means making our research questions legible through social scientific lenses. We must also accommodate our sense of "appropriate progress toward degree" to allow for time in the field and the acquisition of necessary skills to conduct that research, including, where necessary, the acquisition of new languages, data analysis techniques, and critical studies of ethnographies as a mode of knowledge production. ${ }^{43}$

We can also welcome and proactively seek out anthropologists and other social scientists for our faculties, pursuing joint appointments with appropriate departments and developing ongoing intensive public conversations on campus and at our conferences that fully engage these issues. Anthropology is especially well poised to be open to these collaborations. The politics of the majority of sociocultural anthropologists today echo the commitment to progressivism that frames so much of the work in American Studies. And while the rise of cultural studies sparked an initial turf war for some anthropologists about who owns the concept of "culture," this has died down now and has given way to greater openness to nonanthropological work. ${ }^{44}$

NYU anthropologist Faye Ginsberg recognizes the potential crossover institutionally, noting that since the 1970s, more and more US anthropologists have chosen to work "at home." Many of these people, she notes, "pay attention to situations of cultural transformation 'from below,' enabling them to include, as a part of their analysis, a sophisticated and nuanced understanding of what is driving certain kinds of social change, as well as the dilemmas that are facing social actors in these circumstances," ${ }^{45}$ a description that surely resonates with scholars in American Studies. Even the job market may help. More and more anthropologists are choosing to work on the United States, but the number of jobs in that specialty in anthropology remains few owing to the legacies of the field's formation and of area studies configurations. Thus, increasing numbers of anthropologists might find in American Studies a rewarding intellectual home. Creative, aggressive recruiting is key.

Not all of us, of course, may want to retool in order to take on ethnographic work, even if we do want to investigate issues that are embedded in the enactment of daily life. ${ }^{46}$ For this reason, we should investigate team research, uniting humanities scholars with those in the social sciences, jointly developing 
research questions and modes of exploration. While this sharing of credit is common in the sciences, it is still rare in the humanities, built as we are on a tradition of individual measures of scholarly output based on the solo monograph ${ }^{47}$ Ultimately, senior scholars must overhaul the criteria of tenure to more accurately assess collaborative productions so that our field, and new scholars entering it, can benefit from the types of exploration that demand multiple contributors and that exceed the abilities of any one scholar, either in range of expertise demanded or in scope and scale.

\section{Being Based Abroad}

But what about the tens of thousands of specialists on the United States working outside the United States? What are the implications of my call for ethnographic work for those scholars?

First, let me be clear that I am not suggesting that all scholars must undertake fieldwork to do important and compelling work on the United States. Far from it. Many, many topics and issues do not demand on-site analysis. Yet, I am definitely arguing here that we should not have to limit ourselves to those topics and issues, but rather should include the preparation for and practice of doing on-site research into our training programs as one mode of structuring our research questions. There is no getting around the fact that to do such research takes money and, often, extended time away from home, wherever home may be. Anthropologists have acknowledged this for decades, and I think we should too. But for those specialists on the United States who want to take up these issues and cannot spend extended time in the United States, other options abound. As James Watson has so ably shown in his marvelous edited collection, Golden Arches East: McDonald's in East Asia, a study by several anthropologists of how people in Korea, Japan, Taiwan, and Singapore use McDonald's restaurants in their countries, many important cultural processes can be investigated without leaving home. ${ }^{48}$

By positing "America" in the world - as idea, as symbol, as political actor and producer of goods - as the object of analysis, scholars can devise projects that analyze the spread of ideas, products, and practices associated with the United States anywhere in the world that the United States has a political, economic, military, or cultural impact. The influence of hip hop-style dancing on Indian film musicals, or the composition of rap in post-9/11 Japanese music videos, or the move toward tuition-based higher education in Germany, or the spread of Kentucky Fried Chicken clones in Hungary can all be investigated through textual analysis combined with fieldwork focusing on the production, consumption, and circulation of ideas, products, and modes of social interaction. These types of research also offer opportunities for the formation of transnational research teams, again helping us redefine not only our questions, but also our ways of finding answers. 


\section{Closing Thoughts}

I feel strongly that we must engage more fully with the performative dimensions of everyday life: how people make meaning out of the ideas, texts, practices, and beliefs available to them and how they continually reshape those practices and reconstruct their lives and the lives of the communities to which they belong. These active practices of construction and reconstruction always take place in a complex force field of possibilities enabled and limited by historical, political, and economic dimensions, as well as social formations. I don't believe that ethnography is a panacea, magically allowing us to understand the active constitution of lives. It has many limitations, including the potential pitfall of presentism, and many ethical challenges, past and present, based on asymmetries of power, to which we must be attentive. Nonetheless, I believe it is an indispensable tool if we want to move beyond the implicitly text-based analyses that, with a few exceptions, continue to dominate in US American Studies.

I urge our intellectual community to commit to active transformation of our field and to debate the ways that this should be done in order to more fully embrace the social sciences. By combining our traditional strengths in literary analysis and visual and material culture studies with selected social science methodologies, especially ethnography, we can produce more dynamic investigations into everyday lives and their performative dimensions. And, our long-standing strengths in American Studies in social history can help our work steer clear of the presentism that can diminish some ethnographically based studies, unmooring them from the pasts that shape the realm of the possible in the present.

Critics may say that such dimensions are impossible to measure and my attempting to do so, no matter my caveats, runs the risk of simplifying through some sort of positivistic analysis an inherently unruly and necessarily unmeasurable field. Others may assert that the work I am arguing for already exists, but is most often delineated as part of ethnic studies programs and discussions. In either case, my assertion is that we must find ways to increase the role of ethnography in our training and analyses in American Studies and, above all, to institutionalize it in our programs as we move firmly into the twenty-first century. It should become a central part of our field from training to publications. Such a call has resonance both domestically and abroad.

Ultimately, I argue that ethnographic research can help us grasp more vigorously the complex ways in which people actively constitute communities and meanings. I think that our politics demands it. And I think the time to do it is now. Without this understanding, our abilities to contribute to social change will be attenuated, just when the academy at large is moving to ever-greater commitments to public engagement. 


\section{Notes}

1. Although the discipline of history is sometimes considered both a humanities discipline and a social science, more often its methods and mode of argumentation align it with the humanities. Recent publications in American Studies, like Paula Chakravarty and Denise Ferreira da Silva, eds., "Race, Empire and the Crisis of the Subprime," a special issue of the American Quarterly 64, no. 3 (2012), includes a number of contributors with backgrounds in geography and economics, and may indicate a growing, active embrace of the social sciences, especially if such perspectives become more and more integrated into ongoing research across the field and are not limited to special issues around selected topics. The importance of this type of integration of the social sciences is marked by the Council of Editors of Learned Journals naming this issue as the cowinner of the Best Special Issue award, indicating as well the potential of such an approach to enlarge the interdisciplinary audience for American Studies as a field.

2. This article grows out of my participation in a very stimulating roundtable discussion at the 2005 national meetings of the American Anthropological Association. The roundtable, titled Interdisciplinary Ethnography, was organized by Carrie Lane, an American Studies specialist, and included John Caughey, Virginia Dominguez, Quetzal Castaneda, and Carol Stack. I thank them all for their discussions online prior to the meetings and during the roundtable itself. I also thank Richard Ellis and the American Studies Program at the University of Birmingham in the United Kingdom for the opportunity to first try out these ideas during a keynote speech at his institution in 2006. Discussions with Curtis Marez, recent editor of the $A Q$, provided helpful critiques that enabled me to strengthen my arguments, as did extremely helpful commentary by Janice Radway and anonymous reviewers. I thank them all for their thoughtful engagement with these arguments. Caughey's article is "The Ethnography of Everyday Life: Theories and Methods for American Culture Studies," American Quarterly 34, no. 3 (1982): 222-43.

3. See Jeffrey J. Williams, "The Statistical Turn in Literary Studies," The Chronicle of Higher Education, Vol. 57 (18), 2011. Unpaginated.

4. While the institution of tenure certainly accounts for some of this, it alone cannot explain these contours that reflect thirty years of hiring practices and multiple generations of scholars.

5. Mary L. Dudziak and Leti Volpp, eds. "Legal Borderlands: Law and the Construction of American Borders." Special issue, American Quarterly 57, no. 3 (2005).

6. For example, the University of Michigan, with approximately 56 percent of its core faculty associated with English or history, also includes one core member in each of the following disciplines: biology, education, film and video, law, musicology, Native American Studies, public health and anthropology, Slavic languages, and sociology/public policy. Small clusters emerge in anthropology (three), Asian languages and cultures (three), social work (four), and psychology (six), giving this very large program of thirty-four core faculty and sixty-eight affiliates somewhat more strength in the social sciences than most. However, most of the social science practitioners are in the affiliated, not core, faculty category, again indicating a possibility but not a probability that a student would have to strongly engage with those disciplines.

From these tabulations the following is clear: 1) Each program is different-no two have the same configuration of affiliated faculty. For example, The University of Minnesota lists seven affiliated faculty in political science and six in geography, whereas Yale University lists only one in political science and none in geography; 2) Most programs retain the core strength in English and history, and 3) American Studies programs seem to attract a wide variety of "fellow travelers" ranging from library studies, to public health, to education, to social work, to architecture, and even (one faculty member each) biology and mathematics.

7. Given my current appointment in an anthropology department, you might think that this argument is coming from someone outside the field (in terms of training, political and epistemological stakes, faculty location, or institutional engagement with the ASA over a period of time). So, I should note that my current appointment is very recent, resulting from a move to the University of Illinois as of January 2007. Prior to that I spent fourteen years on the American Studies program core faculty at the University of Iowa, teaching undergraduates and $\mathrm{PhD}$ students in that program, after receiving a 1993 PhD in American Studies from Yale. For me, American Studies has been and continues to be a capacious intellectual home, but one that, over the past decade or so, I've come to see as unnecessarily limited by its (largely unexamined) humanities biases.

As my own work in American Studies has changed, so too has my willingness and commitment to engage with social science methods and modes of conceiving of research questions. In addition to now being more comfortable self-reflexively asking what constitutes my "data set" as evidence in my research, I have increasingly become an advocate of ethnography and fieldwork as additional tools for American Studies practitioners. I have guided American Studies dissertations that use these modalities as well, including recent dissertations by Kristin Solli, "North of Nashville: Country Music, National Identity, and Cultural Politics in Norway" (University of Iowa, 2006) and Ulrich Adelt, "Black, White, and Blue: Racial Politics of Blues Music in the 1960s" (University of Iowa, 2007), now available as Blues Music in the Sixties: A Story in Black and White (New Brunswick, NJ: Rutgers University Press, 2010). 
8. In American Quarterly 3, no. 3 (1982): 222-43, especially pages 225-28. Caughey, who holds a PhD in anthropology from the University of Pennsylvania, was an important member of Penn's American Civilization faculty, taking up a position there in 1970. He now teaches in the American Studies program at the University of Maryland, College Park.

9. Akil Gupta and James Ferguson, eds., "Discipline and Practice: 'The Field' as Site, Method, and Location in Anthropology," in Anthropological Location: Boundaries and Grounds of a Field Sciences (Berkeley: University of California Press, 1997), 36 (emphasis in original).

10. Kathleen Stewart, Ordinary Affects (Durham, NC: Duke University Press), 2007.

11. Joao Biehl, "Medication is Me Now: Human Relations and Political Life in the wake of Global AIDS Treatment Programs," paper presented at the University of Illinois at UrbanaChampaign Anthropology Department, Sept. 26, 2008. I thank Dr. Biehl for providing me with a copy of this paper.

12. Margaret Mead, Coming of Age in Samoa (New York: Mentor Books, 1928; reprint

13. Among the key texts for these debates are: James Clifford and George E. Marcus, eds., Writing Culture: The Poetics and Politics of Ethnography (Berkeley: University of California Press, 1986); George E. Marcus and Michael Fischer, Anthropology as Cultural Critique: An Experimental Moment in the Human Sciences (Chicago: University of Chicago Press, 1986); Renato Rosaldo, Culture and Truth: The Remaking of Social Analysis (Boston: Beacon, 1989); George E. Marcus, Ethnography Through Thick and Thin (Princeton, NJ: Princeton University Press, 1998); Kamala Visweswaran, Fictions of Feminist Ethnography (Minneapolis: University of Minnesota Press, 1994); and Alejandro Lugo, ed., Gender Matters: Rereading Michelle Z. Rosaldo (Ann Arbor: University of Michigan Press, 2000).

14. See, for example, Karin Narayin, "How Native is the 'Native'Anthropologist?" in American Anthropologist 95 (3): 19-34.

15. For example, Ruth Behar, Translated Woman: Crossing the Border with Esperanza's Story (Boston: Beacon Press, 1993).

16. Marcus, cited above. And see Akhil Gupta and James Ferguson, Anthropological Locations: Boundaries and Grounds of a Field Science (Los Angeles: University of California Press, 1997)

17. George Marcus, "Ethnography in/of the World System: The Emergence of Multi-Sited Ethnography," Thick and Thin, 79-104.

18. Marcus, Thick and Thin, 90.

19. Occasionally self-reflexive projects turn the academy into a field site itself. See the current project "Ethnography of the University," a collaboratively produced ethnography involving student and faculty researchers, coordinated by professors Nancy Abelmann (anthropology), William Kelleher (anthropology), and Peter Mortensen (English) at the University of Illinois at UrbanaChampaign, available at www.eotu.uiuc.edu.

20. Certainly, there are research initiatives for which fieldwork is irrelevant, specifically some, but not all, historical studies, but since such a concerted strand of American Studies is concerned with the cultural products or cultural perceptions of living populations, there are innumerable arenas in which fieldwork might be a useful tool. I should note here, too, that the use of oral histories, which does have some presence in American Studies practice, can be a useful correlative to participant observation. It can help address the potential emphasis on presentism that ethnographies can be limited by, but by definition oral histories are solo narrations of events, presenting one person's point of view, and do not substitute for an immersion in community life. In addition, the strong strand of material culture studies in American Studies can be approached from an historical ethnographic point of view, as a sort of historical archaeology rather than an archaeology of socalled prehistories.

21. I thank Cinda Nofziger and Danielle Rich for preparing this data. In devising this schema, they counted as articles the following items: articles, presidential addresses, special columns, essays, and forums. Not included are eight short responses to a special on-line issue of the American Quarterly (51, no. 2 [1999]). It should be noted also that I examined the ten-year period ending in 2005. In the time since then, some additional relevant works have appeared, including, for example, two articles in a special edition American Quarterly 58, no. 3 (2006), guest edited by Carolyn de la Pena and Siva Vaihyanathan, titled "Rewiring the 'Nation': The Place of Technology in American Studies." In her piece "Flexible Technologies of Subjectivity and Mobility across the Americas" (891-914), Felicity Schaeffer-Grabiel draws on interviews with Mexican and Colombian women for her discussion of their use of new technologies to refashion their sense of identity. Also in that volume, Caitlan Zaloom drew on her research working on the floor of the Chicago Board of Trade to construct her piece "Markets and Machines: Work in the Technological Sensoryscapes of Finance" (815-37). Zaloom is now an associate professor in the NYU Social and Cultural Analysis Program, which houses the American Studies PhD at NYU, discussed later in this article. Zaloom holds a PhD in anthropology from the University of California at Berkeley.

22. Shank received his training in the American Civilization Program at University of Pennsylvania and represents part of that legacy of social scientific integration with the humanities. 
23. Email correspondence with former $A Q$ editor Marita Sturken, Nov. 6, 2007.

24. For example, see several articles in American Quarterly 60, no. 3 (2008), such as Adrian Felix's "New Americans or Diasporic Nationalists?: Mexican Migrant Responses to Naturalization and Implications for Political Participation." This trajectory may reflect to some degree the location of the journal now at USC (2002-2014), the home of a department of American Studies and Ethnicity that embraces ethnographic methods and the priorities of recent editors and editorial board members. Later in 2014, the journal will move to its new home, the University of Hawai'i at Manoa, under the editorial direction of Mari Yoshihara of the American Studies program there. Undoubtedly, as it has with each relocation, the journal will benefit from and be shaped by the particular strengths and intellectual priorities of its host program.

25. "In the Wake of Katrina: New Paradigms and Social Visions," edited by Clyde Woods, American Quarterly, vol. 61, no. 3, Special Issue, September, 2009

26. Without further research, it is hard to know how to interpret these data about dissertations. The numbers and percentages do not fluctuate widely over this ten-year period; that is, no trend upward or downward is visible. The vast majority of dissertations (using ethnographic methods) are coming out of American Studies departments, although some are from history or joint degrees with folklore and anthropology. It may be that thus far some of these scholars are publishing in related fields.

27. Some of our most exciting historical work (like Lawrence Levine's Highbrow/Lowbrow: The Emergence of Cultural Hierarchy in America (Cambridge: Harvard University Press, 1990.)) does this too, in a sense building an argument about intellectual history through ethnographic readings of historical social practices.

28. Caughey, "The Ethnography of Everyday Life," 242.

29. Ibid., 242, 243.

30. Murray G. Murphey, “American Civilization at Pennsylvania," pt. 2, American Quarterly 22 , no. 2 (Summer 1970), 489-502. For a later discussion of the development of the department and the tensions between the social sciences and literary studies, see Murray G. Murphey, "American Civilization in Retrospect," American Quarterly 31, no. 3 (1979): 402-406. For passionate defenses of the department prior to its dismantling in the mid-1990s, see the section "Speaking Out: SAS Closings," in the University of Pennsylvania's paper, Almanac, Tuesday, October 19, 1993, 5-7, for statements by Murray G. Murphey and Melvin Hammarberg. I thank Janice Radway for urging me to integrate a discussion of Penn's legacy into this article.

31. George Lipsitz, "Learning to Listen," American Quarterly 42, no. 4 (1990): 615-36.

32. Janice Radway, Reading the Romance: Women, Patriarchy, and Popular Literature (Chapel Hill: University of North Carolina Press, 1984). Radway completed the book while on the American Civilization faculty at Penn. After multiple printings, it remains heavily cited and widely included in American Studies syllabi.

33. Heather Paxson, speaking on the video What is Fieldwork?, produced by the Massachusetts Institute of Technology (MIT) anthropology department. Accessed June 30, 2008. Available free at http://techtv.mit.edu/file/663. This video is a good introduction to some of the possibilities and challenges that fieldwork can present through the perspectives of three MIT anthropology faculty members.

34. Tanya Erzen, Straight to Jesus: Sexual and Christian Conversions in the Ex-Gay Movement (Berkeley: University of California Press, 2006).

35. Ibid., 188.

36. Ibid., 230.

37. David Schneider, as told to Richard Handler, Schneider on Schneider: The Conversion of the Jews and Other Anthropological Stories (Durham, NC: Duke University Press, 1995), 212.

38. For example, in 2007 Brown University reported (Brown Alumni Magazine, Fall 2007) that its current freshman class included 14 percent of students who will be the first in their families to attend college, the highest number ever for that institution. While public institutions, and especially community colleges, may provide greater access to higher education than in the past for students from working class households, the percentage of these students continuing on to a $\mathrm{PhD}$ is small. And among first-generation college goers who get graduate degrees, the percentage of those choosing the humanities over the sciences (which are seen as more employable) is even smaller. For a discussion of obstacles faced by first-generation college students see Renny Christopher, "Damned If You Do, Damned If You Don't: How do Working Class Students End Up at Working Class Colleges and Universities?" accessed November 8, 2007, www.aaup.org/AAUP/pubsres/ academe/w003/JA/feat/chri.htm.

39. Anthropologists certainly must grapple with similar issues of comfort and discomfort as they cross community boundaries, and similar issues of social class and social categorizations obtain. They may, however, be more prepared because the issue of the researcher's personal positioning vis-a-vis those of the community with which he or she is working is a central part of the training. This would be an issue to be attentive to whether the researcher is working in a lab of astrophysicists at NASA or among a group of artisans in an agricultural community in the Southwest, 


\section{Jane Desmond}

for example. It is not my attempt here to valorize anthropologists but rather to indicate that some of the challenges that they deal with are ones that could be of use to us as well.

40. And, as one reader of this piece noted, it will also mean that American Studies faculty will have to become involved in their institutional review boards (IRBs). Stringent guidelines for conducting research with humans, mainly targeted toward preventing abuses in the hard sciences, have also resulted in strict protocols, even for conducting formal interviews. Negotiating the requirements of university IRBs and continuing to work with IRBs to educate them more fully about ethnographic research and the conduct of participant observation will place an additional burden on American Studies faculty.

41. See Andrew Ross's books Fast Boat to China: Corporate Flight and the Consequences of Free Trade-Lessons from Shanghai (New York: Pantheon Publishers, 2006; Vintage, 2007) and The Celebration Chronicles: Life, Liberty, and the Pursuit of Property Value in Disney's New Town (New York: Ballantine, 1999).

42. Personal communication by email, American Quarterly editor Curtus Marez, August 2008.

43. At a time when graduate colleges are calling for swifter completion of degrees, the possibility that fieldwork may extend the time to degree is a tricky issue. However, this possibility is just that, a possibility and not a necessity. We should consider ways of realigning training and research approaches with an attentive eye to helping our students move efficiently through degree programs. Fieldwork can be regarded not simply as an "add on" to what is already there, but as a different way of doing things.

44. See Virginia R. Dominguez, "Disciplining Anthropology," in Disciplinarity and Dissent in Cultural Studies, Cary Nelson and Dilip Gaonkar eds. (New York: Routledge Press, 1996), 37-61.

45. Faye Ginsberg, "Ethnography and American Studies," Cultural Anthropology 21, no. 3 (2006): 487-95 (quote on page 488). As an example of an anthropological text edited by an anthropologist with a joint appointment in ethnic studies, see my colleague Martin Manalanson's highly praised collection Cultural Compass: Ethnographic Explorations of Asian America (Philadelphia: Temple University Press, 2000).

46. For those who wish to gain a second area of expertise post- $\mathrm{PhD}$, there are some models. For example, the University of Illinois at Champaign-Urbana offers faculty fellowships for "second area study." Those with these awards spend a year studying in a department or college of the university outside their area of expertise. Certainly similar border crossing could be less formally arranged on other campuses.

47. Again, the timing may be salubrious. As Cathy N. Davidson and others have noted, the production of knowledge in a digital age is changing the notion of authorship just as radically as poststructural senses of the "death of the author," a la Roland Barthes, have done previously. Contingent, changing, collaborative modes of production are a hallmark of some ways of learning, researching, and teaching in a digital environment. See Cathy N. Davidson and David Theo Goldberg's The Future of Thinking: Learning Institutions in a Digital Age (Cambridge, MA: Massachusetts Institute of Technology Press, 2010).

48. James L. Watson, ed., Golden Arches East: McDonald's in East Asia, 2nd ed. (Stanford, CA: Stanford University Press, 2006). 